elastic end of the scale, giving lower values of $k$ An 'index of reinforcement' was defined as the ratio of $k$ before and after compounding and vulcanization. For natural rubber this index is higher than for synthetics. This is reflected in the greater difficulty experienced in vulcanizing the synthetics. The movement toward the elastic end of the scale was demonstrated by analysis of the partial vulcanization (that is, 'scorching') of rubbers in terms of $\psi$ and $k$ values.

Values of $\psi^{\prime}$ and $k^{\prime}$ in the case of extension are characteristic for each rubber, but differ from $\psi$ and $k$ for the same materials.

The data of Hahn and Gazdik (India Rubber World, 51,$103 ; 1941)$ on the slow creep of rubbers in shear give values of $k$ and $\psi$ which are in accord with the performance of the engine mounting compounds described by these authors. For a given value of $\psi$ the smallest ereep is obtained with the lowest value of $k$.

Dr. Scott's paper, entitled "Rheological Problems in the Rubber Industry", discussed a variety of problems in which the rheological properties of rubber are of great importance, and showed how the better understanding of these properties might assist in the control of technological processes.

Dr. Scott took a different line from the previous speakers, representing the properties by a plot of $d \sigma / d t$ (rate of shear) against $S$ (shearing stress). One can recognize specific types of flow curve, such as viscous, pseudo-viscous, plastic, etc., which can be related to the suitability of the material in any given circumstances. In the plasticization of rubber, the incorporation of filling ingredients requires first, good wetting properties, which means high fluidity under the action of small forces, and secondly, the breaking down of aggregates of filler particles, which necessitates high shearing stresses, and therefore high viscosity. These apparently opposite requirements can be satisfied by a certain type of flow curve.

The moulding of unvulcanized rubber is related to other rheological properties. The moulded article must retain its shape. This requires (1) the absence of elastic recovery, and (2) the presence of a yield value, so that the article will not deform under its own weight. The latter property can be assessed from the flow curve. Other examples of rheological significance are the coating of fabrics with rubber, which requires ready penetration into the fabric, and the building up of tyres, etc., which requires good self-adhesion, and means the flowing of one rubber surface into the other. Vulcanization represents the suppression of flow, while reclaiming may be regarded as the recovery of the flow properties which have been suppressed by vulcanization. Methods of assessing dégree of vulcanization, for example, by so-called 'permanent set' tests, and the study of reclaiming thus come within the scope of rheology.

Dealing with methods of measuring the flow characteristics of rubber, Dr. Scott discussed the Williams parallel plate plastometer, extrusion methods, and the Mooney (shearing disk) plastometer, and the sort of information which can be obtained from them. None of these methods provides a uniform rate of shear throughout the specimen, which he considers essential for the fundamental study of rheological properties. Finally, he suggested that the study of the rheological behaviour of rubbers in relation to technological processes on one hand, and to their molecular structure on the other, opens up the possibility of producing rubbers having the particular properties which the technologist may require for any given purpose.

A visit was made in the afternoon to the Rubber Service Laboratories of I.C.I. (Dyestuffs) Ltd., at Blackley, by permission of the delegate directors. Members of both societies were welcomed on arrival by Dr. W. J. S. Naunton. The principal aspects of the handling and testing of natural and synthetic rubbers were illustrated in the laboratories, by a number of demonstrations which emphasized the broad rheological field covered by rubber-like materials.

\section{RECENT ADVANCES' IN ORGANIC CHEMICAL METHODS}

A $\mathrm{T}$ a meeting of the London and South Eastern Counties Section of the Institute of Chemistry on April 21, Dr. E. R. H. Jones, of the Imperia] College of Science and Technology, gave a lecture on "Recent Advances in Organic Chemical Methods". $\mathrm{He}$ said that spectacular advances which have characterized contemporary organic chemistry are largely to be attributed to vast improvements in the technique of the isolation, purification, examination and synthesis of organic compounds, and both new and improved physical and chemical methods have been extensively utilized. It is ever the aim of the organic chemist to employ methods involving the mildest possible conditions and the minimum quantity of material, a trend determined principally by his growing preoccupation with labile compounds of biological importance.

Notable advances made in distillation technique are attributable to the influence of the ever-growing petroleum industry. Molecular distillation is becom. ing increasingly popular and has rendered possible the isolation of vitamin A in a crystalline form. Chromatographic analysis has enormously simplified the purification of both naturally occurring and synthetic organic compounds and has provided a valuable new criterion of purity. On the chemical side a number of new reagents have been developed for the separation of particular classes of organic compounds.

The contribution of microanalysis towards recent achievements cannot be easily over-emphasized, and has led inevitably to the universal introduction of micro-methods. Absorption spectroscopy has proved of great service in the isolation and determination of the structure of vitamins and hormones, and although our knowledge of the relationship between structure and light absorption is still largely empirical, a sufficient fund of information is available to give the method a high diagnostic value.

Greater selectivity can now be obtained following the discovery of hydrogenation catalysts of the Raney nickel type and more specific chemical methods of reduction, for example, sodium in liquid ammonia, and calcium-ammonia $\left(\mathrm{Ca}\left(\mathrm{NH}_{3}\right)_{6}\right)$, are being continually developed. The Meewein-Ponndorf reaction is of unique value for the reduction of sensitive aldehydes and ketones, and Oppenauer's demonstration that this reaction can be reversed provides a useful means of oxidizing unsaturated secondary alcohols to ketones which renders un. necessary the protection of unsaturated linkages. Wide popularity has been accorded to such highly specific oxidizing agents as lead tetra-acetate, osmium tetroxide and selenium dioxide. 
The high-temperature nitration of paraffins and substitution chlorination of olefines are recent technical developments of great significance. The $\alpha$-methylenic halogenation reaction can now be conveniently effected in the laboratory under mild conditions by employing $\mathrm{N}$-bromosuccinimide. The remarkable orientating effect of organic peroxides on the addition of hydrogen bromide to olefines has led to the discovery of other chain reactions, of considerable preparative value, initiated by these trigger catalysts.

\section{THE GRID AND SECONDARY POWER STATIONS IN GREAT BRITAIN}

$I_{c}^{N}$ a paper entitled "The Effect of the National Grid on the Operation and Maintenance of Secondary Power Stations" read before the Institution of Electrical Engineers in London on April 1, R. A. W. Connor discusses the status and function of these stations in relation to the Grid in Great Britain, together with some of the running and maintenance problems brought about by Grid operation, and some of the factors affecting cost of production. The paper directs attention to the important part played by the secondary power stations, the efficient and economic operation of which has undoubtedly contributed in no small measure to successful Grid operation, and to the benefit of the supply industry as a whole.

The following conclusions are reached as a result of the study. The general shape of the national load curve will remain for many years and will not necessitate radical changes in station design. The reclassification of every station through its normal working life must continue, and it would be uneconomic to lay down plant or stations specifically to deal with peak loads only. Future load curves may exhibit exceptionally high rates of change of loads during certain periods, but the capacity of secondary stations will increase and it is unlikely that any new plant will have to be relegated to secondary duties until some years of primary station duties have been completed.

Improvement in the average thermal efficiency of secondary stations will continue owing to the relegation to this class of more modern stations with higher steam pressures and temperatures. There is scope for further improvements in operation and maintenance, although running conditions and high banking losses impose a lower limit on station efficiency than is the case with base-load stations. Grid operation with its daily cycle of temperature changes has affected maintenance and repair work in secondary stations, but not seriously or to the detriment of plant.

Owing to the large variations in output encountered under two-shift, one-shift and peak-load operation, and also cue to the high fixed-cost component, all station costs tend to vary in inverse proportion to the kilowatt-hour output, and comparisons need very careful interpretation to be of any value. A characteristic curve, hyperbolic in shape, correlating output and cost, can be built up for any station. Most secondary stations are called upon at varying intervals and seasons to work with very low outputs, in which $\mathbf{r}$ gion the characteristic shows a very sharp upward trend. Due to the predominating effect of running conditions on thermal efficiency and to the sharp upward trend of the unit cost at low outputs, many secondary stations have suffered reductions in thermal efficiency and increased costs as a result of Grid operation. This, however, has enabled the primary stations to operate under base-load conditions and the full financial advantages of 'Grid operation to be realized.

\section{LOCATION OF INDUSTRY IN GREAT BRITAIN}

$T^{-1}$

"HE paper on "Location of Industry" which Mr. R. G. Glenday, economic adviser to the Federation of British Industries, delivered before the Royal Society of Arts on February 10, roundly challenges current views on the location of industry, including some expressed in the Barlow Report, but his emphasis on the background of change against which the problem of industrial location should be viewed cannot fail to be stimulating, although apart from its provocativeness his paper offers little in the way of constructive suggestion. Fundamentally, Mr. Glenday reminds us, the problem of locating a country's industries and urban centres is part of the larger problem of adjusting a population to its environment, and it is the exceptional rate of growth of populations and industries during the last century and $a$ half that has given rise to so many acute economic problems to-day. He regards the closing of the channels of international movement, following on the disappearance of the geographical frontiers of the civilized world by the first decade of this century, as the major event responsible for bringing to a close the era of democracy and free capitalism in many parts of Europe.

The problem of industrial location must be examined against this background, and Mr. Glenday argues next that the two main factors which determined the location of industry in Great Britain, particularly the move northwards in the nineteenth century, were, first, the development of the railway and steamship, coupled with the adoption of free trade, and, secondly, the development of road transport and electrical transmission in the twentieth century. With this, from 1931 onwards, was associated a re-direction of the 'growing-point' of Britain's industrial energies to home rather than to export activities. Most discussions on the location of industry tend to under-estimate the effect of such basic structural innovations, which affect the general lay-out as well as the skeleton of the economic system. Mr. Glenday, like the Federation of British Industries, seems to be rather obsessed with difficulties, but more creative and adventurous minds may profit by his warnings without being deterred by them. He rightly directs attention to the importance-and the difficulty - of deciding which industries and occupations are essential parts of developing urban structures and which can be regarded as independent and mobile. He stresses also the vital importance of timing in industrial progress. The two main questions which require examination in regard to post-war location are first, the probable size and quality of the population involved, and secondly, the probable direction of the forces of economic evolution affecting the occupation of that population. In regard to the first, he observes that in the main the question will be the redistribution of a stationary or even a declining population; and in regard to the second, 